GA-A23001 CONF-981064 -

\title{
IMPURITY CONTROL STUDIES USING SOL FLOW IN DIII-D
}

RECEIVFD

MAR 081999

OS TI

by

M.R. WADE, J.T. HOGAN, R.C. ISLER, R. MAINGI, W.P. WEST, N.H. BROOKS, A.W. LEONARD, T.W. PETRIE, M.J. SCHAFFER, D.N. HILL, S.L. ALLEN, M.E. FENSTERMACHER, C.J. LASNIER, R.D. WOOD, J.A. BOEDO, R. LEHMER, R.A. MOYER, D.G. WHYTE, and J.G. WATKINS

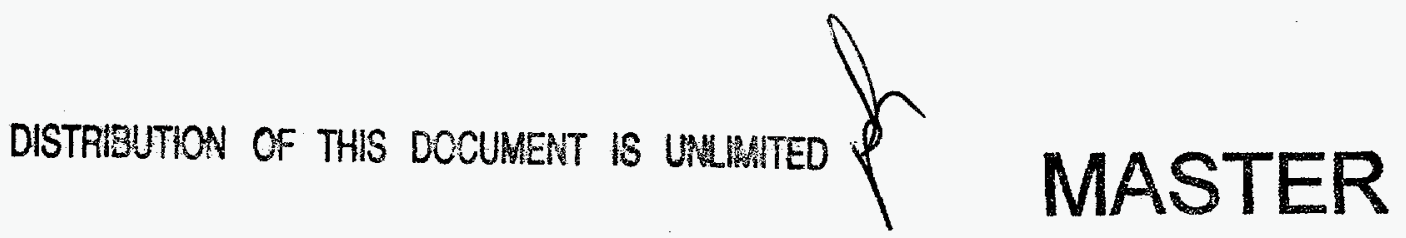

NOVEMBER 1998 


\section{DISCLAIMER}

Portions of this document may be illegible in electronic image products. Images are produced from the best available original document. 
GA-A23001

\title{
IMPURITY CONTROL STUDIES USING SOL FLOW IN DIII-D
}

\author{
by

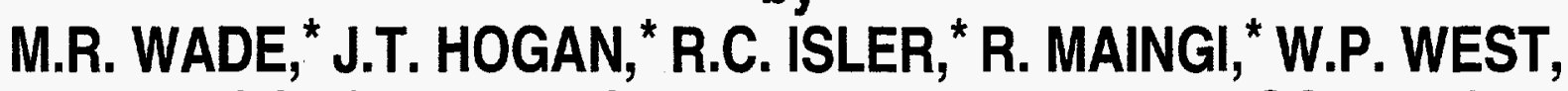 \\ N.H. BROOKS, A.W. LEONARD, T.W. PETRIE, M.J. SCHAFFER, \\ D.N. HILL, † S.L. ALLEN, † M.E. FENSTERMACHER, † C.J. LASNIER, † \\ R.D. WOOD, † J.A. BOEDO, ‡ R. LEHMER, \\ D.G. WHYTE, $\ddagger$ and J.G. WATKINS $\Delta$
}

This is a preprint of a paper presented at the 17th International Atomic Energy Agency Fusion Energy Conference, October 19-24, 1998, Yokohama, Japan and to be published in Nucl. Fusion.

*Oak Ridge National Laboratory, Oak Ridge, Tennessee.

†Lawrence Livermore National Laboratory, Livermore, California.

FUniversity of California at San Dlego, La Jolla, California.

${ }^{\Delta}$ Sandia National Laboratory, Albuquerque, New Mexico.

\author{
Work supported by \\ the U.S. Department of Energy under \\ Contract NoS. DE-AC03-99ER54463, DE-AC05-960R22464, \\ W-7405-ENG-48 and DE-AC04-94AL85000
}

GA PROJECT 30033

NOVEMBER 1998 


\title{
IMPURITY CONTROL STUDIES USING SOL FLOW IN DIIL-D*
}

\author{
M.R. WADE ${ }^{\dagger}$ W.P. WEST, D.N. HILL $\stackrel{\ddagger}{\dagger}$ S.L. ALLEN, $\stackrel{\dagger}{\dagger}$ J.A. BOEDO, ${ }^{\Delta}$ N.H. BROOKS,

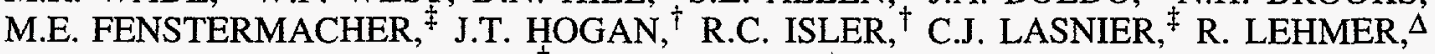 \\ A.W. LEONARD, R. MAINGI ${ }^{\dagger}$ R.A. MOYER, ${ }^{\Delta}$ T.W. PETRIE, M.J. SCHAFFER, \\ J.G. WATKINS, ${ }^{\diamond}$ D.G. WHYTE, $\Delta$ and R.D. WOOD ${ }^{\ddagger}$ \\ DIII-D National Fusion Facility, General Atomics, San Diego, California 92186-5608
}

\begin{abstract}
Experiments on DIII-D have demonstrated the efficacy of using induced scrape-off-layer (SOL) flow to preferentially enrich impurities in the divertor plasma. This SOL flow is produced through simultaneous deuterium gas injection at the midplane and divertor exhaust. Using this SOL flow, an improvement in enrichment (defined as the ratio of impurity fraction in the divertor to that in the plasma core) has been observed for all impurities in trace-level experiments (i.e., impurity level is non-perturbative), with the degree of improvement increasing with impurity atomic number. In the case of argon, exhaust gas enrichment using a modest SOL flow is as high as 17. Using this induced SOL flow technique and argon injection, radiative ELMing $\mathrm{H}$-mode plasmas have been produced that combine high radiation losses $\left(\mathrm{P}_{\mathrm{rad}} / \mathrm{P}_{\text {input }}>70 \%\right)$, low core fuel dilution $\left(\mathrm{Z}_{\text {eff }}<1.9\right)$, and good core confinement $\left(\tau_{\mathrm{E}}>1.0 \tau_{\mathrm{E}, \mathrm{ITER} 93 \mathrm{H}}\right)$.
\end{abstract}

\section{INTRODUCTION}

In a high-power density fusion device, controlling impurities in the scrape-off-layer (SOL) is essential in obtaining high radiative power fractions in the SOL to protect the divertor surfaces from unacceptable heat loads and material erosion while maintaining acceptably low impurity contamination in the core plasma. A key issue in this regard is whether external control of impurities is possible through tailoring of the main ion flow in the SOL. The tailoring of the main ion flow through strong $\mathrm{D}_{2}$ gas injection and simultaneous divertor exhaust has been an integral part of the DIII-D program since 1994 [1-4]. These experiments have demonstrated that induced SOL flow offers several potential advantages and two primary results have been obtained: (1) induced SOL flow improves impurity enrichment in the divertor plasma in both open and closed divertor configurations with argon enrichment values as high as 17 obtained in the highest flow cases; and (2) plasmas with $P_{\text {rad }}^{\text {tot }} / P_{\text {input }}>80 \%$ with a high SOL radiation fraction $\left(P_{r a d}^{S O L}+P_{r a d}^{\text {div }}>60 \%\right.$ of $\left.P_{r a d}^{\text {tot }}\right)$ have been obtained in ELMing $\mathrm{H}$-mode plasmas with confinement $\sim 1.0 \tau_{\text {ITER } 93 \mathrm{H}}, \mathrm{n}_{\mathrm{e}}=0.75 \mathrm{n}_{\mathrm{e}_{\mathrm{GW}}}$, and $\mathrm{Z}_{\mathrm{eff}}<1.9$ using argon as the seeded impurity.

\section{IMPURITY ENRICHMENT STUDIES}

The premise of the "puff and pump" technique used on DIII-D is that through simultaneous deuterium injection near the midplane and divertor exhaust one can augment the bulk plasma ion flow in the SOL sufficiently to overcome the thermal gradient force, which acts to drive impurities toward the core plasma $[5,6]$ Additional benefit may be gained through lowering of the SOL and divertor ion temperature, which increases the frictional force and reduces the thermal gradient force. Experiments have demonstrated that this technique is effective in increasing the enrichment of impurities in the DIII-D divertor [1,2] with the improvement being substantial for higher $Z$ impurities [3] To assess the effectiveness of this process in entraining impurities in the SOL, the typical figures of merit are the exhaust enrichment $\left(\eta_{\text {exh }} \equiv f_{\text {exh }} / f_{\text {core }}\right)$ and compression $\left(C_{e x h} \equiv n_{Z}^{\text {exh }} / n_{Z}^{\text {core }}\right)$. On DIII-D, direct measurement of these quantities are made using charge-exchange recombination (CER) spectroscopy for the core impurity content and a modified Penning gauge for the exhaust gas impurity content. The results from these studies are summarized in Table 1 . The observed exhaust enrichment $\eta_{\text {exh }}$ is

\footnotetext{
*Work supported by the U.S. Department of Energy under Contract Nos. DE-AC03-99ER55563, DE-AC0596OR22464, W-7405-ENG-48, DE-AC04-94AL85000, and Grant No. DE-FG03-95ER54294.

tOak Ridge National Laboratory, Oak Ridge, Tennessee.

‡Lawrence Livermore National Laboratory, Livermore, California.

${ }^{\Delta}$ University of California, San Diego, La Jolla, California.

"Sandia National Laboratories, Albuquerque, New Mexico.
} 
Table 1. Measured enrichment $\left(\eta_{\text {exh }}\right)$ and compression $\left(C_{e x h}\right)$ for various flow levels and impurities

\begin{tabular}{|l|l|l|l|l|l|l|l|l|}
\hline & \multicolumn{1}{|c|}{ Case A } & \multicolumn{2}{c|}{ Case B } & \multicolumn{2}{c|}{ Case C } & \multicolumn{2}{c|}{ Case D } \\
\hline Fueling Location & \multicolumn{2}{|c|}{ Top } & \multicolumn{2}{c|}{ Divertor } & \multicolumn{2}{c|}{ Top } & \multicolumn{2}{c|}{ Divertor } \\
\hline Fueling Rate(D $/ \mathrm{s})$ & \multicolumn{2}{|c|}{$1.05 \times 10^{22}$} & \multicolumn{2}{c|}{$1.05 \times 10^{22}$} & \multicolumn{2}{c|}{$5.6 \times 10^{21}$} & \multicolumn{2}{c|}{$5.6 \times 10^{21}$} \\
\hline & $\eta_{\text {exh }}$ & $C_{\text {exh }}$ & $\eta_{\text {exh }}$ & $C_{\text {exh }}$ & $\eta_{\text {exh }}$ & $C_{\text {exh }}$ & $\eta_{\text {exh }}$ & $C_{\text {exh }}$ \\
\hline Helium & 1.1 & 6.1 & 0.9 & 4.3 & n/a & n/a & n/a & n/a \\
Neon & 2.3 & 14.2 & 1.2 & 7.8 & 1.6 & 6.2 & 1.0 & 4.6 \\
Argon & 17.0 & 85.0 & 6.0 & 28.5 & 3.7 & 11.4 & 2.1 & 6.2 \\
\hline
\end{tabular}

observed to be consistently higher in the top fueling case, indicating a beneficial effect of SOL flow on divertor retention of impurities. The results in Table I also suggest that enrichment is sensitive to the choice of impurity. For example, in the $1.0 \times 10^{22} \mathrm{D} \% \mathrm{~s}$ case, helium enrichment increases $\sim 20 \%$, neon enrichment increases $\sim 90 \%$, and argon enrichment increases $\sim 200 \%$ when comparing the top $D_{2}$ fueling case (Case A) with the divertor fueling case (Case B). Similar trends in argon enrichment have been inferred from SPRED UV measurements of argon line radiation in the core and divertor plasmas [3]. Analysis shows that this strong $\mathrm{Z}$ dependence is consistent with a combined neutral ionization and ion transport picture of impurity entrainment in the divertor [3].

Besides the improvement in impurity enrichment, several advantageous by-products arise from the application of this technique. First, at a high flow level, the SOL broadens and its density increases to $1.5 \times 10^{19} \mathrm{~m}^{-3}$ while the electron temperature remains approximately $10 \mathrm{eV}$. Such profiles provide excellent screening of impurities emanating from the vessel wall and an excellent environment for impurity radiation. Secondly, the ELM amplitude is reduced by approximately a factor of two relative to standard ELMing $\mathrm{H}$-mode conditions [7]. This reduction is accompanied by a proportional increase in the ELM frequency such that the time-integrated energy carried out by the ELMs is approximately the same, but the instantaneous perturbation on the edge and divertor plasma induced by each ELM is much smaller. Modeling has also shown that the ELM dynamics are important in the obtainable impurity enrichment with higher frequency ELMs leading to improved enrichment [8]. Note that these changes are accomplished without significant impact on the core energy confinement.

\section{RADIATIVE DIVERTOR PLASMAS}

Motivated by the favorable argon enrichment values obtained in the induced SOL flow case, recent experiments on DIII-D have focused on producing radiative divertors using the "puff and pump" technique with argon as the seeded impurity. These experiments have produced radiative plasmas that possess many of the aspects required by the radiative "solution" embodied in the ITER design criteria. In particular, radiative fractions up to $75 \%$ with concomitant heat flux reduction (a factor of 4 ) have been achieved simultaneous with good core energy confinement $\left(\tau_{E}=1.1 \tau_{E, \text { ITER93H }}\right)$ and minimal core contamination $\left(\mathrm{Z}_{\mathrm{eff}}<1.9\right)$. This represents the first successful demonstration of radiative divertor operation using a seeded impurity in which all of these requirements are achieved simultaneously. An overview of the results are presented here.

The best radiative discharges to date have been produced in a lower-single-null configuration with $\mathrm{I}_{\mathrm{p}}=1.3 \mathrm{MA}, \mathrm{B}_{\mathrm{T}}=-2.1 \mathrm{~T}, \mathrm{q}_{95}=4.1, \mathrm{~K}=1.75,\langle\delta\rangle=0.28$, and $\mathrm{P}_{\mathrm{NBI}}=11.9 \mathrm{MW}$. In these discharges, a SOL flow is applied through deuterium injection near the symmetry point at the top of DIII-D at rate of $2.45 \times 10^{22} \mathrm{D}^{0} / \mathrm{s}$ throughout the current flattop phase (Fig. 1). This strong $\mathrm{D}_{2}$ flow alone produces plasma conditions in which radiation levels are higher than normally found in ELMing $\mathrm{H}$-mode plasmas. During this phase, the total radiated power [Fig. 1(c)] represents approximately $50 \%(\sim 6.0 \mathrm{MW})$ of the total input power $\left(\mathrm{P}_{\mathrm{NBI}}+\mathrm{P}_{\mathrm{OH}} \approx 11.9 \mathrm{MW}\right)$ with $\mathrm{P}_{\text {rad,div }}: \mathrm{P}_{\text {rad,SOL }}: \mathrm{P}_{\text {rad,core }}$ $(\mathrm{MW})=3.5: 2.0: 0.5$. The peak heat flux incident on the outer divertor target, inferred from IRTV measurements, is $\sim 2.0 \mathrm{MW} / \mathrm{m}^{2}$ [Fig. 1(d)], which is a factor of two lower than the value normally obtained at these power levels with no external gas injection [9]. Carbon is observed to be the dominant impurity in the core plasma with $\mathrm{Z}_{\mathrm{eff}} \approx 1.4$, [Fig. 1(e)] and carbon and deuterium are the main radiating constituents in the divertor.

A further increase in radiation is then observed upon the introduction of argon at $2.0 \mathrm{~s}$, which is injected from the private flux region of the divertor at a rate of $1.26 \times 10^{21} \mathrm{Ar} / \mathrm{s}$. During the argon injection phase, the total radiation increases up to $-75 \%(8.5 \mathrm{MW})$ with $\mathrm{P}_{\text {rad,div: }} \mathrm{P}_{\text {rad,SOL }}: \mathrm{P}_{\text {rad,core }}$ $(\mathrm{MW})=4.3: 2.4: 1.8$. The radiation from the core plasma is localized in the last $10 \%$ of the plasma volume while the radiation in the divertor plasma is distributed fairly evenly over the entire divertor 

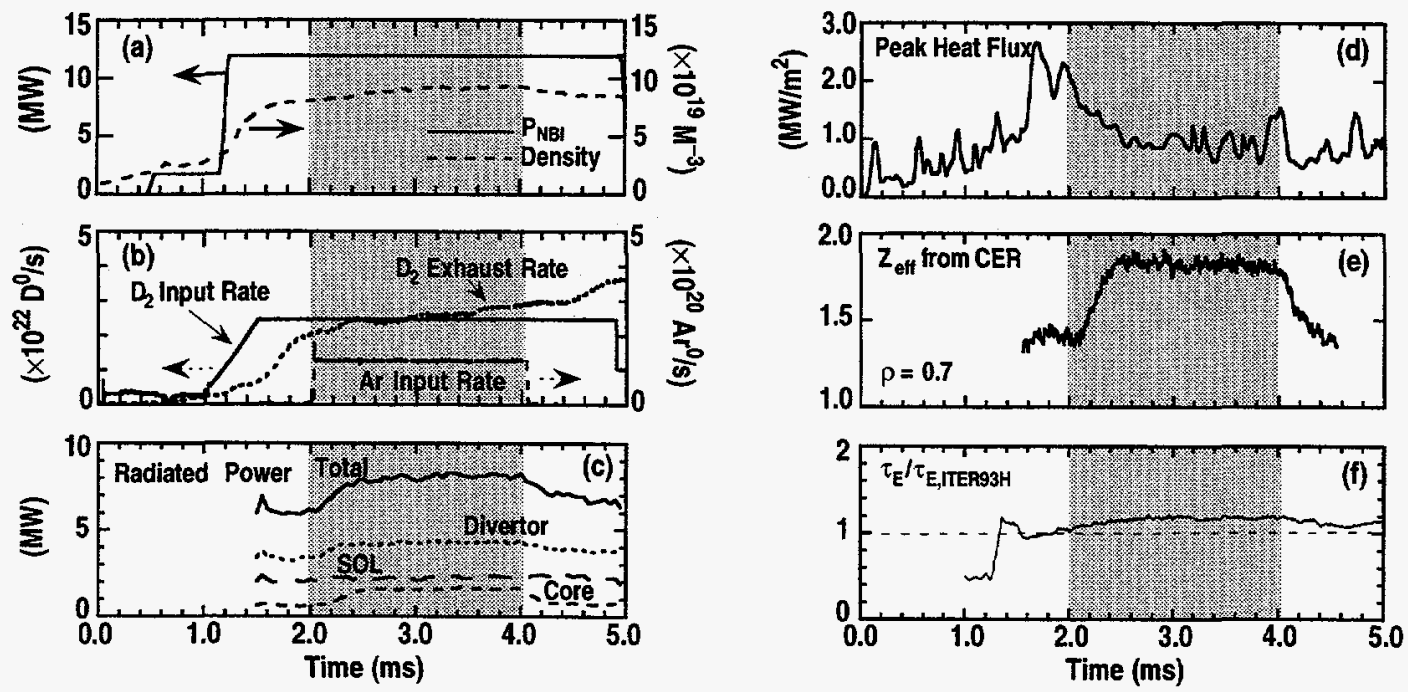

FIG. 1. Temporal evolution of the (a) input power and line-averaged electron density; (b) deuterium input and exhaust rates and argon input rate, $(c)$ radiation power balance; (d) peak heat flux at the outer strike point; $(e) Z_{\text {eff }}$ and $(f) \tau_{E} / \tau_{E, I T E R 93 H}$ in a radiative discharge produced via argon injection simultaneous with strong $D_{2}$ injection and divertor exhaust.

volume (Fig. 2). The increase in core radiation consists almost entirely of line radiation from argon and is consistent with the measured argon concentration $(\sim 0.20 \%)$ in the core plasma. Meanwhile, the increase in the divertor radiation includes roughly equal increases in both carbon and argon radiation; thus, carbon remains the dominant radiator in the divertor. Even though the biggest increase in radiation is observed to come from the core plasma, it is important to note that the divertor radiative efficiency (defined as the ratio of the power radiated in the divertor to the power conducted to the divertor) actually increases substantially during the argon injection phase from $40 \%$ up to $55 \%$. The increase in radiation is accompanied by a factor of 2 decrease (relative to the pre-argon injection phase) in the total and peak heat flux incident on the outer divertor target plates [Fig. 1(d)]. The outward shift of the heat flux profile observed during the argon injection phase is indicative of partial detachment of the outer strike point [Fig. 2(b)]. However, Langmuir probes measurements at the outer strike point suggest that the outer divertor leg remains attached as the particle flux profile remains peaked at the separatrix location. Furthermore, the measured $D_{\alpha} / D_{\beta}>20$ in the vicinity of the OSP, indicating that significant recombination is not occurring [10].

The core carbon fraction does not change during the argon injection phase while the argon fraction increases to $\sim 0.20 \%$, resulting in $Z_{\text {eff }} \approx 1.85$. The incremental $Z_{\text {eff }}\left(i . e ., Z_{\text {eff }}-1=0.85\right.$ ) in this case is a factor of 2 smaller than that predicted by the scaling for radiative plasmas given by Matthews et al. [11]. In fact, the measured incremental $Z_{\text {eff }}$ in these "puff and pump" discharges is found to be consistently lower than the predicted scaling value, regardless of the level of argon (Fig. 3). This is consistent with the fact that the radiation in the DIII-D radiative discharges comes primarily from the divertor plasma; therefore, one might expect that $P_{r a d}$ is not a linear function of $Z_{\text {eff }}$ as suggested by the Matthews scaling law. Global energy confinement is not affected by the introduction of argon with $\tau_{\mathrm{E}}=1.7 \tau_{\mathrm{E}, \mathrm{TTER} 89 \mathrm{P}}=1.1 \tau_{\mathrm{E}, \mathrm{ITER} 93 \mathrm{H}}$. In fact, there is little variation of energy confinement in these types of discharges over a wide range of radiative fraction $\left(\mathrm{P}_{\mathrm{rad}} / \mathrm{P}_{\mathrm{NBI}}\right)$. Furthermore, local transport analysis reveals little difference in $\chi_{\text {eff }}$ between the $D_{2}$ only cases and the $D_{2}+A r$ cases. These observations are consistent with the observation that there is little deterioration in the edge plasma during the argon injection phase as the pedestal pressure remains approximately the same as in the preargon phase. ELMs remain Type I in character with the ELM frequency increasing to $200 \mathrm{~Hz}$ during the argon injection phase. One final observation is that energy confinement in this regime is insensitive to plasma density, in contrast to results in RI-mode studies on TEXTOR [12].

\section{CONCLUSIONS}

These studies have demonstrated that SOL flow has many inherent benefits for ELMing $\mathrm{H}$-mode operation including: (1) improved impurity enrichment, especially of high $\mathrm{Z}$ impurities; (2) thicker SOL profiles at the midplane; and (3) a factor of two reduction in the heat loss per ELM without any deleterious effects on plasma confinement. Furthermore, a radiative plasma which meets 


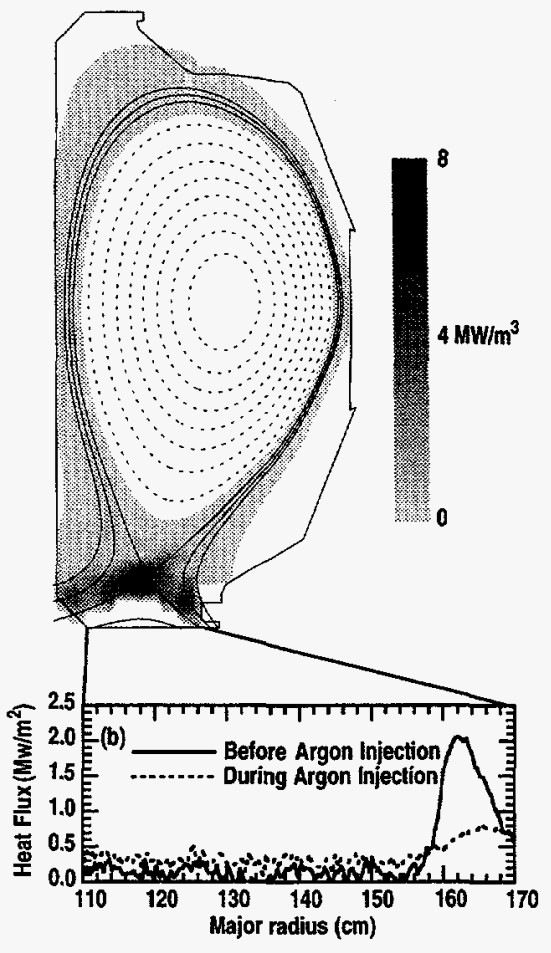

FIG. 2. Two-dimensional radiation profile inferred from bolometry data and the heat flux profile at the divertor target taken at $3.5 \mathrm{~s}$ of the discharge described in Fig. 1.

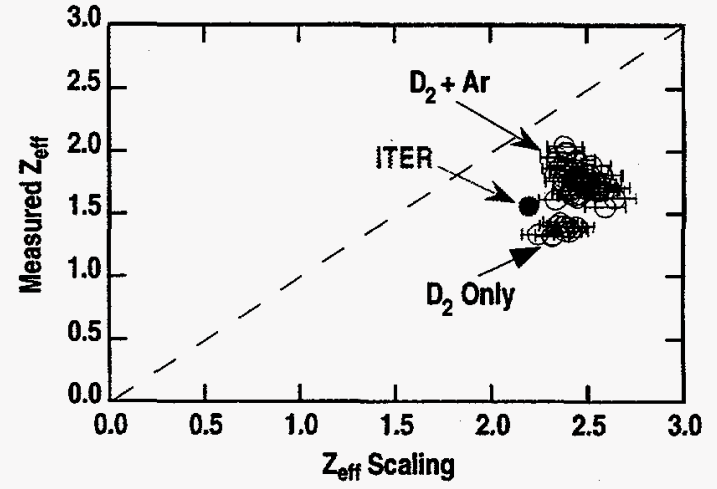

FIG. 3. Measured $Z_{\text {eff }}$ versus the predicted scaling $Z_{\text {eff }}=1+4.5 P_{\text {rad }} Z^{0.12} /\left(S^{0.94} \bar{n}_{e}^{1.89}\right)$ where $P_{\text {rad }}$ is the total radiation power, $Z$ is the charge of the primary impurity, $S$ is the plasma surface area, and $\vec{n}_{e}$ is the lineaveraged density. The horizontal error bars depicted here represent the uncertainty related to the impurity charge to use in the scaling expression (ranging from $Z=6$ (carbon) to $Z$ $=18$ (argon). The ITER data point is calculated using $P_{\text {rad }}=150 \mathrm{MW}, S=1250 \mathrm{~m}^{2}$, $n_{e}=0.96 \times 10^{20} \mathrm{~m}^{-3}$, and $Z=18$ (argon).

all of the relevant criteria embodied in the ITER design has been produced on DIII-D using this technique in combination with argon injection. The core argon fraction in these plasmas $(\sim 0.20 \%)$ is consistent with the maximum fraction allowed in ITER as estimated by computational simulations [13]. Previous analytic estimates show that the maximum heat flux reduction in ITER that could be expected given this argon fraction would be $\approx 50 \%$ [14]. However, assuming that an argon enrichment consistent with this experiment (i.e., $\eta_{e x h}=3.0$ ) can be achieved on ITER, then this percentage would increase to over $67 \%$, consistent with the ITER criteria that $P_{\text {target }} / P_{\text {loss }}=33 \%$. The results described in Section 2 indicate that even higher divertor enrichment of argon $\left(\eta_{\text {exh }} \approx 20\right)$ can be obtained using induced SOL flow and that a more closed, baffled divertor geometry may increase the argon enrichment further. Finally, it is worth noting that the "solution" described here embodies many of the favorable aspects of a "hybrid" radiative solution in which low- $Z$ impurity radiation predominates in the divertor and radiation from a high- $Z$ impurity embellishes this divertor radiation while providing additional radiation in the core plasma.

\section{REFERENCES}

[1] SCHAFFER, M.J., et al., Nucl. Fusion 8, 1000 (1995).

[2] SCHAFFER, M.J., et al., J. Nucl Mater 241-243, 585 (1997).

[3] WADE, M.R., et al., "Impurity Enrichment Studies with Induced Scrape-Off Layer," Nucl. Fusion (accepted for publication) (1998).

[4] WADE, M.R., et al., J. Nucl. Mater., (in press) (1998).

[5] NEUHAUSER, J., et al., J. Nucl. Mater. 121, 194 (1984).

[6] KRASHENINNIKOV, S.I., Contrib. Plasma Phys. 28, 465 (1988).

[7] LEONARD, A.W., J. Nucl. Mater. (in press) (1998).

[8] HOGAN, J.T., et al., in Proc. of the 25th EPS Conf. on Plasma Phys. and Contr. Fusion, 1998 (in press).

[9] LASNIER, C.J., et al., Nucl. Fusion 38, 1225 (1998).

[10] ISLER, R.C, et al., Plasma Phys. Contr. Fusion 4, 2989 (1997).

[11] MATTHEWS, G., et al., J. Nucl. Mater. 196-198, 450 (1997).

[12] MESSIAEN, A.M., et al., Phys. Plasmas 4, 1690 (1997).

[13] MANDREKAS, J., et al., Nucl. Fusion 37, 1015 (1997).

[14] POST, D.E., et al., J. Nucl. Mater. 121, 171 (1984). 